\title{
Wernicke's Encephalopathy Following Gastroplasty for Morbid Obesity
}

\author{
Cory Toth, Chris Voll
}

\begin{abstract}
Background: The syndrome of Wernicke's encephalopathy consists of two of four features of (1) dietary deficiency; (2) oculomotor abnormality; (3) cerebellar dysfunction; and (4) confusion or mild memory impairment. Predisposing risk factors include alcoholism, hyperemesis gravidarum and prolonged intravenous feeding. Methods: A 35-year-old female developed refractory emesis, severe weight loss, and hypokalemia following banded gastroplasty for morbid obesity. Reversal of gastroplasty was performed four months following initial surgery. Following reversal, the patient developed confusion, ataxia, leg weakness and nystagmus. Results: Examination of the patient demonstrated disorientation with confusion, vertical nystagmus worse on downgaze, diffuse weakness of the lower extremities, and bilateral dysmetria. Magnetic resonance imaging of the brain demonstrated symmetrical areas of increased $\mathrm{T}_{2}$ signal present bilaterally in the medial thalamic nuclei. The patient did not demonstrate any initial improvement with intravenous thiamine but improved over two months of follow-up. Conclusion: Wernicke's encephalopathy has been reported in the European literature as a complication of gastroplasty, with rare recognition of this clinical entity in the North American literature. This potential complication of gastroplasty may be preventable by nutritional intervention in subjects experiencing severe weight loss and emesis following surgery.
\end{abstract}

RÉSUMÉ: Encéphalopathie de Wernicke suite à une gastroplastie pour obésité morbide. Introduction: Le syndrome de l'encéphalopathie de Wernicke est constitué de deux des quatre manifestations suivantes: 1) des carences alimentaires; 2) des anomalies oculomotrices; 3) une dysfonction cérébelleuse; et 4) de la confusion ou une légère atteinte de la mémoire. Les facteurs de risque incluent l'alcoolisme, l'hyperémésis gravidarum et l'alimentation parentérale prolongée. Méthodes: Une femme de 35 ans a développé des vomissements incoercibles, une perte de poids importante et de l'hypokaliémie suite à une gastroplastie par cerclage pour une obésité morbide. Le cerclage a été retiré quatre mois après la chirurgie initiale. Suite à cette intervention, la patiente a développé de la confusion, de l'ataxie, de la faiblesse des membres inférieurs et du nystagmus. Résultats: À l'examen, la patiente était désorientée et présentait de la confusion, un nystagmus vertical exagéré au regard vers le bas, une faiblesse diffuse des membres inférieurs et une dysmétrie bilatérale. La RMN du cerveau a montré des zones symétriques d'augmentation du signal $\mathrm{T}_{2}$ présentes bilatéralement dans le groupe nucléaire médial du thalamus. Initialement, l'état de la patiente ne s'est pas amélioré lors de l'administration de thiamine intraveineuse, mais il s'est amélioré au cours des deux mois du suivi. Conclusion: L'encéphalopathie de Wernicke a été rapportée dans la littérature Européenne comme complication de la gastroplastie et elle est rarement mentionnée dans la littérature nordaméricaine. Cette complication possible de la gastroplastie peut être prévenue par une intervention nutritionnelle chez les sujets qui présentent une perte de poids importante et des vomissements suite à la chirurgie.

Can. J. Neurol. Sci. 2001; 28: 89-92

Carl Wernicke described a syndrome of acute ataxia, ophthalmoplegia, nystagmus, polyneuropathy, and confusion in 1881. This was six years prior to the description of Korsakoff syndrome by Korsakoff in 1887. Korsakoff did not refer to Wernicke's work but he noted several of the same symptoms and signs described by Wernicke in patients he described with Korsakoff syndrome. Gudden noted in 1896 that symptoms described in both syndromes tended to occur sequentially in several patients. ${ }^{1}$ Many references now refer to the syndrome as Wernicke-Korsakoff syndrome. However, diagnostic criteria for Wernicke's encephalopathy have been defined. Initially, these criteria were the presence of three clinical signs - oculomotor abnormalities, cerebellar dysfunction, and confusion. New criteria have been formulated, with diagnosis of Wernicke's

From the Division of Neurology, Department of Medicine, Royal University Hospital, University of Saskatchewan, Saskatoon, SK, Canada.

ReCEIVEd March 17, 2000. ACCEPTED IN Final FORM OCtOBER 26, 2000. Reprint requests to: Cory Toth, Division of Neurology, Department of Medicine, Royal University Hospital, University of Saskatchewan, 103 Hospital Drive, Saskatoon, SK, Canada S7N 0W8 
encephalopathy requiring two of the following four signs: (1) dietary deficiency; (2) oculomotor abnormality; (3) cerebellar dysfunction; and (4) confusion or mild memory impairment. When applied to 28 alcoholic patients, with neuropathological diagnoses of Wernicke's encephalopathy, interrater reliability for diagnosis was $100 \% .^{2}$

Since the time of Wernicke, an association of thiamine deficiency with Wernicke's encephalopathy has been established. Chronic alcohol abuse, recognized by Korsakoff as being concurrent in patients with Korsakoff syndrome, has been implicated in Wernicke's encephalopathy due to low dietary intake of thiamine and alcohol-associated impairment in the absorption and metabolism of thiamine. ${ }^{3}$ There is also a hypothesized direct neurotoxic effect of alcohol as well. Thiamine deficiency is now a well-established cause of Wernicke's encephalopathy.

Almost all cases of Wernicke's encephalopathy described in the literature which are not related to alcoholism are related to malnutrition or malabsorption. These conditions, including anorexia nervosa, persistent emesis, intravenous feeding, hyperemesis gravidarum, and prolonged fasting, are all associated with poor vitamin intake. ${ }^{3}$

We describe the case of a 35-year-old female who presented with confusion, nystagmus, and ataxia following reversal of a banded gastroplasty performed for morbid obesity. Poor dietary intake, clinical examination, radiological examination, and subsequent improvement over long-term follow-up suggest the diagnosis of Wernicke's encephalopathy due to malnutrition and malabsorption as a result of the gastroplasty.

\section{Case Report}

A 35-year-old female presented to a general surgeon in October 1997 with morbid obesity refractory to dietary and lifestyle changes. In March 1998, she had a banded gastroplasty performed without intra-operative or immediate postoperative complications and she was discharged home one week following surgery. Over the following two months, she lost 3035 kilograms and presented to her surgeon and to emergency rooms on numerous occasions for persisting abdominal pain, difficulty with swallowing and emesis. Following three emergency room assessments in which she was treated for hypokalemia and dehydration, she requested reversal of the banded gastroplasty. Reversal of the previous gastroplasty was performed in July 1998. The patient received intravenous dextrose solutions pre- and postoperatively. The day following surgery, the patient was noted to have visual hallucinations. Over the next three days, the patient became more disoriented and difficulty with gait was noted. Four days following surgery, the patient was unable to walk three meters, had difficulty with coordination, and complained of diplopia as well as burning pain in both lower extremities. Diarrhea was present postoperatively. There was no hyponatremia noted pre- or postoperatively. Computerized tomography (CT) of the head was performed and found to be normal. Following this imaging, the Neurology service was consulted.

Past history was remarkable for psychiatric illness with bipolar disorder requiring numerous prior electroconvulsive therapies, alcohol and substance abuse, borderline personality disorder, and bulimia. The patient had not had any alcohol abuse since 1995 and did not abuse alcohol prior to either gastroplasty or its reversal. She was a former prostitute with prior intravenous drug abuse and numerous tattoos. Recent blood tests for the human immunodeficiency virus and hepatitis viruses were negative. Prior surgeries consisted of cholecystectomy, breast size reduction, and tubal ligation. Medications prior to admission consisted of benzodiazepines and amitryptyline. The patient's only allergy was codeine. Family history was remarkable for bipolar disorder in her mother and maternal grandmother.

On examination, all vital signs were normal. Neurological examination revealed the patient to be oriented to name only. Inattention and impersistence were noted during examination. Immediate memory was limited to three digits on the digit span test, with impairment secondary to inattention. Short-term anterograde memory was impaired based upon the three item recall test. Long-term retrograde memory was impaired based on questions of recall of the patient's personal history, geographical, and famous events. There was no evidence of focal cognitive dysfunction. Vertical nystagmus was present in the primary position, and upbeating nystagmus was noted on downgaze. There was no horizontal or torsional component to the nystagmus. Extraocular movements were full. Facial strength was normal. Strength was normal to the upper extremities. Strength testing of the lower extremities revealed diffuse weakness (right/left): hip flexor (4-/4-), hip extensor (4/4), quadriceps (4/4), hamstrings (4-/4-), hip abductors (4+/4+), hip adductors $(4+/ 4+)$, foot evertor $(4 / 4)$, tibialis anterior $(5 / 5)$, extensor hallucis longus (4-/4-), plantar flexor (4/4). Mild hyperreflexia was noted to the lower extremities with downgoing plantar responses. Sensory exam was normal. Mild upper extremity dysmetria was present bilaterally. Drift was absent. Asterixis was present. General examination revealed only multiple abdominal surgical scars and obesity.

Laboratory examinations at that time revealed only mild hypokalemia. Lumbar puncture was performed, with an opening pressure of $14 \mathrm{~cm} \mathrm{H}_{2} \mathrm{O}$. Laboratory studies are listed in the Table. Serum transketolase activity could not be measured within our laboratory.

Table: Laboratory Studies of Serum, Urine, and CSF

$\begin{array}{ll}\text { Laboratory Tests } & \text { Lab Value } \\ \text { Serum } & \\ \text { White blood cells } & 8.6 \times 109 / \mathrm{L} \\ \text { Hemoglobin } & 147 \mathrm{~g} / \mathrm{L} \\ \text { Urea } & 1.8 \mathrm{mmol} / \mathrm{L} \\ \text { Creatinine } & 58 \mathrm{umol} / \mathrm{L} \\ \text { Random Glucose } & 5.4 \mathrm{mmol} / \mathrm{L} \\ \text { Magnesium } & 0.75 \mathrm{~g} / \mathrm{L} \\ \text { Albumin } & 41 \mathrm{~g} / \mathrm{L} \\ \text { Folate } & 8.2 \mathrm{ug} / \mathrm{mL} \\ \text { Vitamin B12 } & 440 \mathrm{pg} / \mathrm{mL} \\ \text { Vitamin E } & 18.2 \mathrm{umol} / \mathrm{L} \\ \text { Alanine Aminotransferase } & 30 \mathrm{U} / \mathrm{L} \\ \text { Aspartate Aminotransferase } & 32 \mathrm{U} / \mathrm{L} \\ \text { Alkaline Phosphatase } & 64 \mathrm{U} / \mathrm{L} \\ \text { Gamma Glutamyltransferase } & 28 \mathrm{U} / \mathrm{L} \\ \text { Urine } & \\ \text { Porphobilinogens } & \text { Negative } \\ \text { Porphyrins } & 92 \mathrm{mg} / 24 \mathrm{hr} \\ \text { CSF } & \\ \text { White blood cells } & 1 \times 106 / \mathrm{L} \\ \text { Red blood cells } & 0 \times 106 / \mathrm{L} \\ \text { Glucose } & 3.3 \mathrm{mmol} / \mathrm{L} \\ \text { Protein } & 0.46 \mathrm{~g} / \mathrm{dL} \\ \text { Gram Stain/Culture } & \mathrm{Negative} \\ \text { Cytology } & \text { Negative } \\ \text { Anti-GQ1b Ab } & \text { Negative } \\ \end{array}$




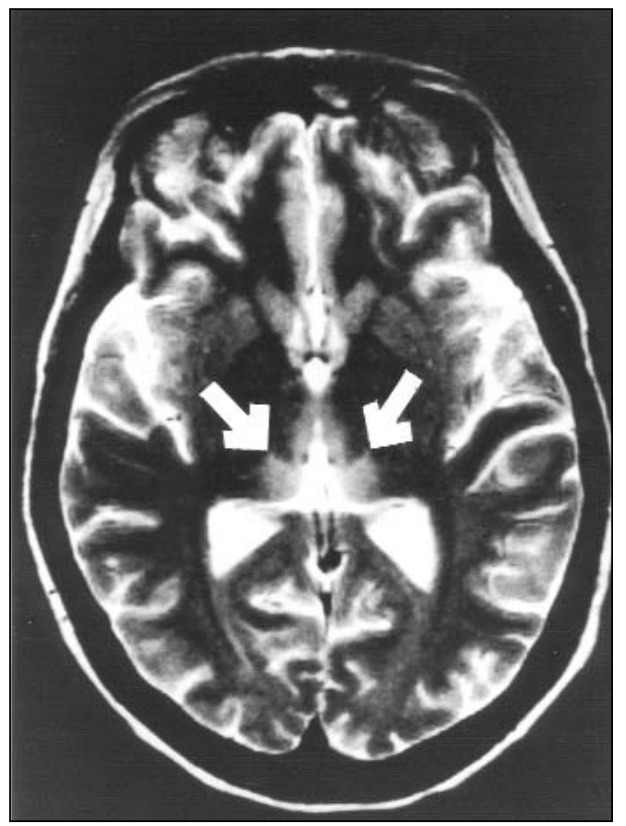

Figure: Magnetic resonance imaging of the brain revealing symmetrical areas of increased $T 2$ signal bilaterally within the medial thalamic nuclei (arrowheads).

Differential diagnosis at that time consisted of porphyria, Miller-Fisher variant of Guillain-Barre syndrome, central pontine myelinolysis, and Wernicke's encephalopathy. The patient was admitted to the Neurology service and commenced on therapy with thiamine intravenously, as well as folate, magnesium and multivitamins delivered intravenously with intravenous glucose solution. The clinical examination did not reveal any improvements over the first few days of intravenous therapy.

Magnetic resonance imaging (MRI) of the brain was performed and revealed symmetrical areas of increased $\mathrm{T}_{2}$ signal in the medial thalamic nuclei (Figure). There were no other abnormalities noted to the brain parenchyma, and the remainder of MRI examination of the head was normal. Electroencephalography (EEG) revealed diffuse nonspecific slowing of background activity. Blink reflex testing showed bilateral prolongation of the R2 latency, suggesting conduction delay in the pontine tegmentum bilaterally. Nerve conduction studies performed four days after admission revealed normal conduction velocities, normal amplitudes and normal $\mathrm{F}$ wave latencies in the lower extremities. The right peroneal motor amplitude was reduced. Electromyography of tibialis anterior and gastrocnemius bilaterally was normal. All other investigations were normal. A diagnosis of Wernicke's encephalopathy secondary to gastroplasty and prolonged malnutrition and emesis was made, given the presence of all four criteria for Wernicke's encephalopathy: (1) dietary deficiency; (2) oculomotor abnormality; (3) cerebellar dysfunction; and (4) altered mental state or memory impairment. Intravenous therapy consisting of glucose, thiamine, folate and multivitamins were provided for a total of five days before oral therapy with thiamine, folate and multivitamins was continued for the rest of the hospital admission.

The remainder of the hospital admission was unremarkable except for a surgical site abscess which was drained percutaneously, and a urinary tract Klebsiella infection. The patient was transferred to a Neurorehabilitation unit with good functional recovery after a month long stay. Ten months following initial admission, she is doing well with full mobility, and part-time employment. Examination during follow-up revealed mild dysmetria and mild up-beating nystagmus present in primary position and on downgaze.

\section{Discussion}

The clinical diagnosis of Wernicke's encephalopathy was initially based upon presence of the clinical triad of oculomotor dysfunction, ataxia and confusion. New criteria require presence of two of four signs: (1) dietary deficiency; (2) oculomotor abnormality; (3) cerebellar dysfunction; and (4) altered mental state or memory impairment. ${ }^{2}$ This patient had an etiology for dietary deficiency, demonstrated oculomotor dysfunction, cerebellar dysfunction and altered mental state. It is assumed that her nutritional state prior to initial gastroplasty was adequate, and that following gastroplasty, prolonged emesis and intravenous feeding, thiamine deficiency developed producing the syndrome of Wernicke's encephalopathy. Our patient did present with lower extremity weakness. Peripheral neuropathy due to thiamine deficiency can also occur concurrently with Wernicke's encephalopathy. However, the presence of brisk deep tendon reflexes in our patient suggests that an upper motor neuron dysfunction was at least partially responsible for lower extremity weakness. We believe the most likely cause of lower extremity weakness in our patient was corticospinal tract involvement within the basis pontis or internal capsule.

In the continuum of Wernicke-Korsakoff syndrome, bilateral, symmetrical punctate lesions are found in the area surrounding the third and fourth ventricles and cerebral aqueduct. Midbrain and cerebellar lesions are responsible for symptoms and signs of Wernicke's encephalopathy, while lesions in the diencephalon produce the features of Korsakoff syndrome. ${ }^{3}$

The use of MRI as a diagnostic tool in Wernicke's encephalopathy has assisted in the diagnosis of the entity. In a postmortem-verified histopathological study, areas of high signal surrounding the third and the fourth ventricles and aqueduct on T2-weighted MRI images were correlated with spongy disintegration of the neuropil at autopsy. ${ }^{4}$ Hyperintense lesions on MRI in cases of Wernicke's encephalopathy have been reported surrounding the third ventricle and aqueduct, ${ }^{5,6}$ caudate, ${ }^{7}$ or with gadolinium enhancement at only the mammillary bodies. ${ }^{8}$ Follow-up imaging studies demonstrate disappearance or diminished changes to affected areas. ${ }^{5}$ Specificity and sensitivity of the use of MRI and MRI findings in the diagnosis of Wernicke-Korsakoff syndrome is unknown.

The pathophysiology of Wernicke-Korsakoff syndrome remaines poorly understood. Thiamine has a metabolic role as a coenzyme for transketolase, and also plays a role in nerve conduction and in ion transport. When an excess of carbohydrates in the diet relative to thiamine occurs, the development of thiamine deficiency states such as Wernicke's encephalopathy can occur. Thiamine deficiency has been found to lead to decreased levels of thiamine-dependent enzymes and a series of adverse metabolic effects can occur including decreased levels of intracellular energy and accumulation of glutamate. ${ }^{9}$ One possible mechanism relates to abnormalities in the metabolism of transketolase, an enzyme that requires the active form of thiamine, thiamine pyrophosphate, as a cofactor. While measurement of serum thiamine levels are unreliable for the diagnosis of Wernicke's encephalopathy due to low sensitivity and specificity, thiamine deficiency in thiamine leads to an elevation in the red blood cell transketolase, which can be assayed. A serum 
transketolase assay is most sensitive when performed before and after a thiamine pyrophosphate challenge. ${ }^{10}$

Gastroplasty is a surgical approach to restrict gastric size in severe obesity refractory to conservative therapies. Recognized complications of vertical banded gastroplasty ${ }^{11}$ include intractable vomiting and sequelae due to malabsorption of calcium and iron. If gastric size is too small, ingestion of large volumes of liquids or normal diet often leads to vomiting. ${ }^{12}$ Three recognized sequelae of persistent vomiting are: (1) sudden death from protein malnutrition; (2) refeeding syndrome; and (3) Wernicke-Korsakoff syndrome. ${ }^{12}$ Wernicke's encephalopathy as a complication of gastroplasty has been reported previously, with most cases occurring within weeks of the surgery. ${ }^{13-16}$ Development of Wernicke's encephalopathy months to years after gastrectomy has been reported in few patients. ${ }^{17}$ Wernicke's encephalopathy following a long latency period after gastroplasty has been reported in one case. ${ }^{18}$ In our patient, Wernicke's encephalopathy developed after reversal of gastroplasty. We speculate that thiamine levels were made further deficient by the inadequate nutrition in conjunction with administration of intravenous dextrose solutions during the perioperative and postoperative period and led to Wernicke's encephalopathy in the postgastroplasty reversal period. Other neurologic complications reported following gastric restriction surgery include polyneuropathy, burning feet syndrome, meralgia paresthetica, and myelopathy. ${ }^{16}$

Treatment for Wernicke's encephalopathy includes abstinence from alcohol and adequate vitamin supplementation. Patients should receive thiamine 100-200 mg intravenously daily. Electrolyte imbalance should also be corrected. ${ }^{10}$ Anaphylactic reactions to IV thiamine unrelated to the dose are rare. ${ }^{19}$ Magnesium, a cofactor for transketolase, should be given as magnesium sulfate ( 1 to $2 \mathrm{ml}$ intravenously or intramuscularly of a $50 \%$ solution) with thiamine to correct thiamine resistance and the frequently accompanying hypomagnesemia. ${ }^{10}$ Thiamine treatment leads to improvement in ocular abnormalities within hours in $35 \%$ of patients, improvement in confusion within days in $80 \%$, and incomplete improvement in ataxia within a few days in less than $50 \%$ of patients. ${ }^{20}$ There are no laboratory studies which predict prognosis. We speculate that thiamine deficiency in our patient was severe leading to delay in clinical improvement despite thiamine provision, and the slow rate of clinical improvement may have occurred due to severe thiamine deficiency.

We do not have pathological evidence of our clinical diagnosis, but our patient meets the clinical criteria for Wernicke's encephalopathy as outlined by Caine et al. ${ }^{2}$ Since discharge from hospital, confusion, ataxia and lower extremity weakness have improved, with persistance of mild vertical nystagmus, which is similar to the follow-up course reported in previous literature. ${ }^{18}$ Following prolonged intravenous thiamine provision and intensive neurorehabilitation, our patient has done well and now lives independently.

\section{CONCLUSION}

Wernicke's encephalopathy must be considered as a possible complication of gastroplasty performed for morbid obesity. The malabsorption resulting from the surgical gastric resection as well as malnutrition resulting from poor dietary intake, intravenous administration of carbohydrate solutions, and concomitant prolonged emesis following the surgical procedure can lead to the development of Wernicke's encephalopathy. We recommend parenteral vitamin supplementation in all patients undergoing gastroplasty, consisting of $100 \mathrm{mg}$ of intravenous thiamine, $5 \mathrm{mg}$ of intravenous folate, and 1-2 $\mathrm{ml}$ of magnesium sulfate in $50 \%$ solution daily during their postoperative period, until adequate oral diet can be achieved.

\section{REFERENCES}

1. Gudden H. Klinische und anatomische beitraege zur kenntniss der multiplen alkoholneuritis nebst bemerkungen ueber die regenerationsvorgaenge im peripheren nervensystem. Arch Psychiatr Nervenkr 1896; 28:643-741.

2. Caine D, Halliday GM, Kril JJ, Harper CG. Operational criteria for the classification of chronic alcoholics: identification of Wernicke's encephalopathy. J Neurol Neurosurg Psychiatry 1997; 62:51-60.

3. Victor M, Adams RD, Collins GH. The Wernicke-Korsakoff syndrome and related neurological disorders due to alcoholism and malnutrition. 2nd ed. Philadelphia: FA Davis, 1989.

4. Suzuki S, Ichijo M, Fujii H, Matsuoka Y, Ogawa Y. Acute Wernicke's encephalopathy: comparison of magnetic resonance images and autopsy findings. Intern Med 1996; 35(10):831-834.

5. Gallucci M, Bozzao A, Splendiani A, Masciocchi C, Passariello R. Wernicke encephalopathy: MR findings in five patients. AJR Am J Roentgenol 1990; 155(6):1309-1314.

6. Omer SM, al Kawi MZ, al Watban J, et al. Acute Wernicke's encephalopathy associated with hyperemesis gravidarum: magnetic resonance imaging findings. J Neuroimaging 1995; 5(4):251-253.

7. Ohkoshi N, Ishii A, Shoji S. Wernicke's encephalopathy induced by hyperemesis gravidarum, associated with bilateral caudate lesions on computed tomography and magnetic resonance imaging. Eur Neurol 1994;34(3):177-180.

8. Shogry ME, Curnes JT. Mamillary body enhancement on MR as the only sign of acute Wernicke encephalopathy. AJNR Am J Neuroradiol 1994;15(1):172-174.

9. Langlais PJ. Pathogenesis of diencephalic lesions in an experimental model of Wernicke's encephalopathy. Metab Brain Dis 1995;10:31-44.

10. Gilroy J. Basic Neurology. New York: Pergamon Press, 1990.

11. Kolanowski J. Surgical treatment for morbid obesity. Br Med Bull 1997;53(2):433-444.

12. Mason EE. Starvation injury after gastric reduction for obesity. World J Surg 1998; 22(9):1002-1007.

13. Oczkowski WJ, Kertesz A. Wernicke's encephalopathy after gastroplasty for morbid obesity. Neurology 1985; 35(1):99-101.

14. Seehra H, MacDermott N, Lascelles RG, Taylor TV. Wernicke's encephalopathy after vertical banded gastroplasty for morbid obesity. BMJ 1996; 312(7028):434.

15. Christodoulakis M, Maris T, Plaitakis A, Melissas J. Wernicke's encephalopathy after vertical banded gastroplasty for morbid obesity. Eur J Surg 1997; 163(6):473-474.

16. Abarbanel JM, Berginer VM, Osimani A, Solomon H, Charuzi I. Neurologic complications after gastric restriction surgery for morbid obesity. Neurology 1987;37(2):196-200.

17. Shimomura T, Mori E, Hirano N, Imamura T, Yamashita H. Development of Wernicke-Korsakoff syndrome after long intervals following gastrectomy. Arch Neurol 1998;55(9):12421245.

18. Albina JE, Stone WM, Bates M, Felder ME. Catastrophic weight loss after vertical banded gastroplasty:malnutrition and neurologic alterations. JPEN 1988;12(6):619-620.

19. Morinville V, Jeannet-Peter N, Hauser C. Anaphylaxis to parenteral thiamine (vitamin B1). Schweiz Med Wochenschr 1998;128(44):1743-1744.

20. Rowland, LP(ed.). Merritt's Textbook of Neurology. Ninth Ed. Philadelphia: Williams and Wilkins, 1995. 